\title{
Inhibition of Collagen-Induced Platelet Aggregation by Antibodies to Distinct Types of Collagens
}

\author{
By Leopold BALLEISEN, ${ }^{*} \dagger$ Hans NOWACK, $\ddagger$ Steffen GAY§ and Rupert TIMPL $\ddagger$ \\ *Department of Medicine and Institute for Arteriosclerosis Research, University of Münster, Münster, \\ West Germany, $\ddagger$ Max-Planck-Institut für Biochemie, Martinsried, West Germany, and §Institute of \\ Dental Research, University of Birmingham, Birmingham, AL 35294, U.S.A.
}

(Received 18 June 1979)

\begin{abstract}
Aggregation of platelets by fibrils formed from collagens type I, II and III could be inhibited by coating the fibrils with anti-collagen antibodies or Fab fragments. Similar results were obtained in a clot-retraction assay. Inhibition was achieved with stoichiometric amounts of antibodies and was specific for each type of collagen. Aggregation caused by a mixture of type-I and -III collagens could only be inhibited by a mixture of antibodies against both collagens. The data show that each interstitial collagen is capable of interacting with platelets and do not support the concept of an outstanding activity of type-III collagen.
\end{abstract}

Aggregation of platelets by collagen is considered as a useful system in vitro for studying the adherence of platelets to subendothelial structures in injured blood vessels (Michaeli \& Orloff, 1976). Previous studies have established that soluble collagens are poorly active in aggregation, but become very efficient when precipitated in the form of fibrils (Muggli \& Baumgartner, 1973; Gordon \& Dingle, 1974; Jaffe \& Deykin, 1974; Brass \& Bensusan, 1974; Balleisen et al., 1975a; Barnes et al., 1976). Collagen exists in the body in several polymorphic variants, and three genetically distinct types, I, II and III, are well characterized (Fietzek \& Kühn, 1976; Miller, 1976). These types of interstitial collagens were all able to aggregate platelets, but type-III collagen was on a weight basis more active than the other two collagens (Balleisen et al., 1975a). This finding correlated with immunohistological data suggesting a high content of type-III collagen in the subendothelial region of the vessel wall (Gay et al., 1975). The strong interaction between platelets and type-III collagen was confirmed by Hugues et al. (1976), and these authors concluded that the lower activity found for type-I collagen was not an inherent property of this protein, but could be due to contamination by type-III collagen.

Since aggregation of platelets depends on a particular quaternary structure of collagen, it is difficult to explore the mechanism at the molecular level. Monovalent antibody fragments to fibrinogen were successfully used to study platelet aggregation caused by thrombin (Tollefsen \& Majerus, 1975).

$\dagger$ To whom reprint requests should be addressed at Institut für Arterioskleroseforschung, Westring 3, D-44 Münster, West Germany.

Vol. 184
We have previously described specific antibodies to type-I, -II and -III collagens (Nowack et al., 1976). Here, we used these antibodies to characterize platelet aggregation by various types of collagens, using a specific inhibition assay.

\section{Materials and Methods \\ Preparation of collagen fibrils}

Type-I and -III collagens were extracted with $1 \mathrm{M}$ $\mathrm{NaCl}$ from foetal bovine skin and purified by salt precipitation and chromatography on DEAEcellulose (Timpl et al., 1975). As judged by sodium dodecyl sulphate/polyacrylamide-gel electrophoresis, contamination of type-I collagen by type-III collagen was negligible, and vice versa. Type-II collagen was solubilized from bovine articular cartilage by limited digestion with pepsin and purified as described by Miller (1972). Solutions of these collagens in $0.1 \mathrm{M}$ acetic acid $(0.5 \mathrm{mg} / \mathrm{ml})$ were dialysed at $4-8^{\circ} \mathrm{C}$ against $0.02 \mathrm{M}$-sodium phosphate buffer, $\mathrm{pH} 7.4$. During dialysis collagen formed an opaque suspension of fibrils, which, as shown previously (Balleisen et al., 1976), was very efficient in aggregating platelets.

\section{Purification of antibodies and Fab fragments}

Purified antibodies were prepared from rabbit antisera against type-I, -II and -III collagens and rendered specific for the antigen by immunoadsorption. As judged by agglutination and radioimmunoassays, the antibodies showed a strong reaction with the collagen used for immunization and did not crossreact with the other two types of collagen (Nowack et al., 1976). Antibodies to bovine serum albumin and bovine fibrinogen were prepared by a similar immunoadsorption procedure. Immunoglobulin G 
was purified from a rabbit antiserum to type-I collagen on DEAE-cellulose and then digested with mercuripapain (Worthington, Freehold, NJ, U.S.A.) by an established procedure (Edelman \& Marchalonis, 1967). Fab fragments were isolated from the digest by immunoadsorption on type-I collagen (Beil et al., 1973). The fragments were further purified on Bio-Gel P-100 and were found by gel diffusion not to contain Fc antigen. All antibody solutions were finally dialysed against $0.02 \mathrm{M}$-phosphate buffer, pH7.4.

Immuno-electron-microscopy of antibody-coated collagen fibrils

A suspension of collagen fibrils $(0.2 \mathrm{mg} / \mathrm{ml})$ in $0.02 \mathrm{M}$-phosphate buffer, $\mathrm{pH} 7.4$, was incubated with an equal volume of purified antibody $(0.2 \mathrm{mg} / \mathrm{ml})$ for $30 \mathrm{~min}$ at $20^{\circ} \mathrm{C}$ and non-bound antibody was subsequently removed by centrifugation $(1000 \mathrm{~g}$ for $10 \mathrm{~min})$. The fibrils were washed three times with $0.02 \mathrm{M}$-phosphate buffer, $\mathrm{pH} 7.4$, resuspended in the buffer and incubated with peroxidase-conjugated goat antibodies to rabbit immunoglobulin $G$ (Miles Laboratories, Kankakee, IL, U.S.A.). Peroxidase was then detected by reaction with 3,3'-diaminobenzidine as oxidizable substrate (Graham \& Karnovsky, 1966). After a further staining of the fibrils with phosphotungstic acid they were examined in the electron microscope.

\section{Platelet-aggregation assay}

For the preparation of platelet-rich plasma, blood was collected from healthy volunteers and prevented from clotting by adding $0.1 \mathrm{vol}$. of $3.8 \%(\mathrm{w} / \mathrm{v})$ sodium citrate. After centrifugation at $90 \mathrm{~g}$ for $10 \mathrm{~min}$ the supernatant fluid was collected and contained 200000-400000 platelets/ $\mu$ l. Platelet aggregation was determined in an aggregometer as described by Born \& Gross (1963). Increase in light transmission was monitored by a linear recorder (Vitatron UR 400). In the reaction $0.45 \mathrm{ml}$ of platelet-rich plasma was mixed with $0.05 \mathrm{ml}$ of a suspension of collagen fibrils and incubated at $37^{\circ} \mathrm{C}$. The minimal aggregation dose of each batch of collagen fibrils was determined as described previously (Balleisen et al., 1975a). In the inhibition assay 1.5-2 times the minimal aggregating dose of fibrils was incubated for $5 \mathrm{~min}$ at room temperature with various amounts of purified antibodies or Fab fragments before addition to the platelets. No difference in the results was observed either when the whole mixture of fibrils and antibodies was added to the reaction or when non-bound antibody was removed from the fibrils by centrifugation.

\section{Fibrin-clot retraction assay}

Platelet-rich plasma $(0.7 \mathrm{ml})$ was mixed with $0.1 \mathrm{ml}$ of collagen fibrils $(200 \mu \mathrm{g} / \mathrm{ml})$ and $0.2 \mathrm{ml}$ of a solution of Arvin in $0.15 \mathrm{M}-\mathrm{NaCl}(12 \mu \mathrm{g} / \mathrm{ml})$. Arvin (Knoll A.G., Ludwigshafen, Germany) is a snake venom from Malayan pit viper (Agkristodon rhodostoma) and resembles in its activity the snake enzyme reptilase, i.e. it causes fibrin-clot formation by release of fibrinopeptide A (Hessel \& Blombäck, 1971). Unlike thrombin, it does not aggregate platelets by itself (Sharp et al., 1968). The mixture was incubated at $37^{\circ} \mathrm{C}$ and the size of the clot was measured at various intervals between 15 and $200 \mathrm{~min}$ of incubation.
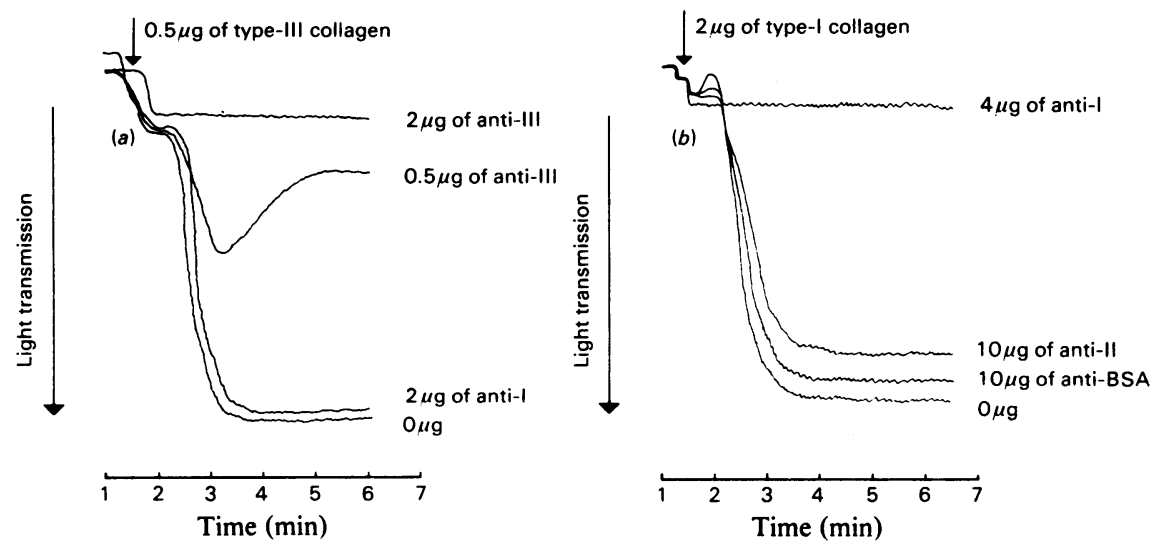

Fig. 1. Inhibition by antibodies of platelet aggregation induced with $0.5 \mu \mathrm{g}$ of type-III collagen (a) or with $2 \mu \mathrm{g}$ of type-I collagen (b)

Antibodies in the amounts indicated were against type-I collagen (anti-I), type-II collagen (anti-II), type-III collagen (anti-III) or bovine serum albumin (anti-BSA); controls without antibody were denoted by $0 \mu \mathrm{g}$. 


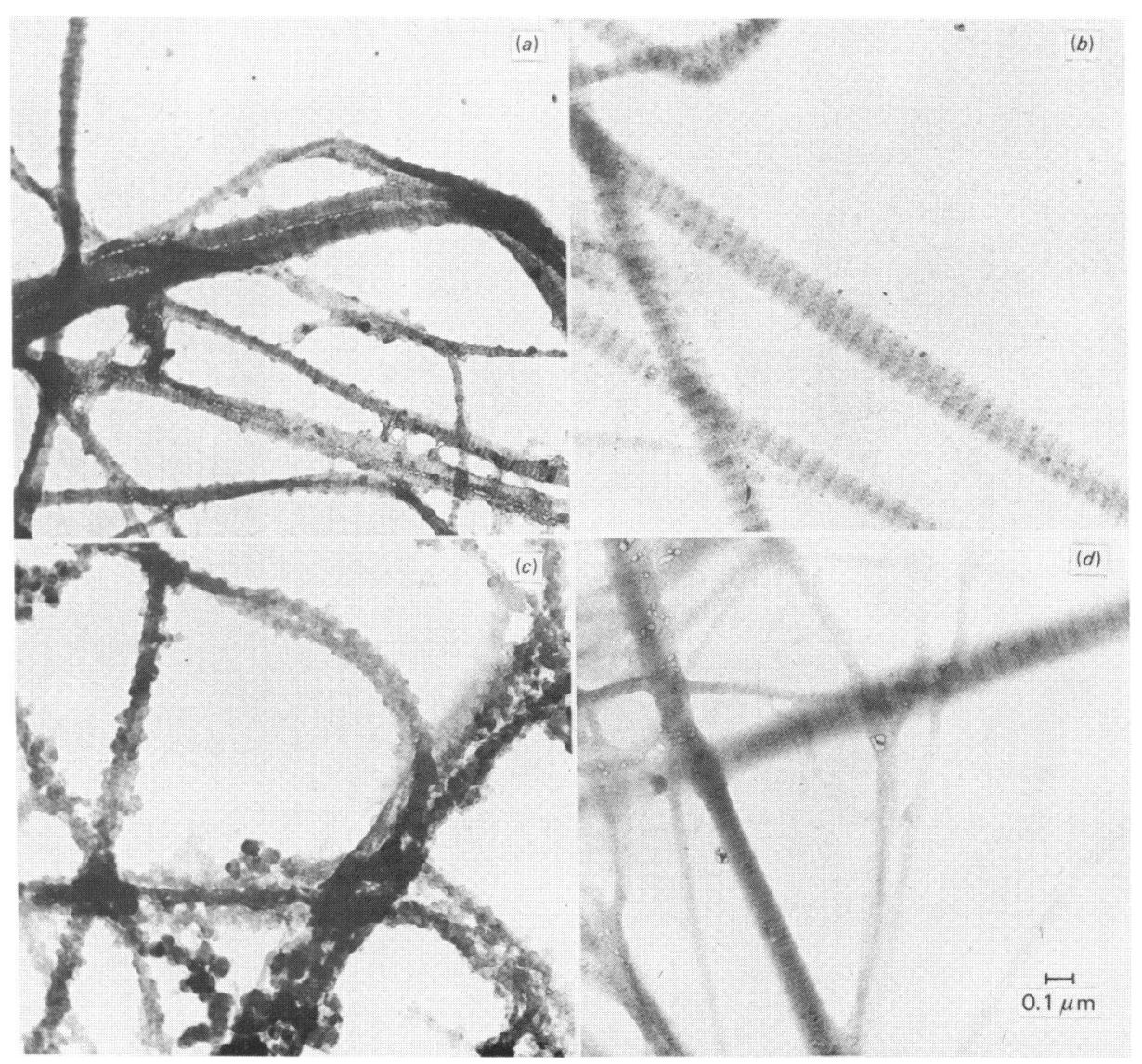

\section{EXPLANATION OF PLATE I}

Observation of antibody coating of collagen fibrils by the indirect antibody-peroxidase technique (a), Type-I collagen fibrils stained with antibodies against type-I collagen; $(b)$, same as $(a)$, but stained with antibodies against type-III collagen; $(c)$, type-III collagen fibrils stained with antibodies against type-III collagen; $(d)$, same as $(c)$, but stained with antibodies against fibrinogen. The second antibody was a peroxidase conjugate of goat anti-(rabbit immunoglobulin G). 

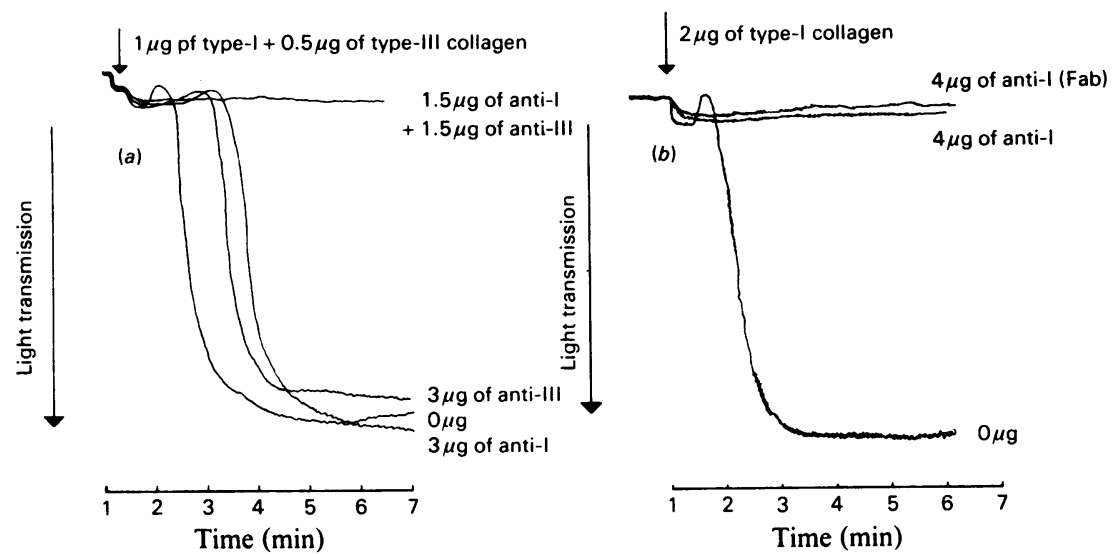

Fig. 2. (a) Inhibition by antibodies of platelet aggregation induced with a mixture of type-I and type-III collagens; (b) comparison of the inhibiting activities of antibodies and Fab fragments

The abbreviations are the same as in Fig. 1.

\section{Results}

\section{Reaction of antibodies with collagen fibrils}

Antibodies to various types of collagens show a strong and specific reaction with soluble collagens in passive haemagglutination and radioimmunoassays (Nowack et al., 1976). We have now examined the reaction of the same antibodies with collagen fibrils by electron microscopy by using the indirect antibodyperoxidase technique. Plates $1(a)$ and $1(c)$ show that type-I collagen and type-III collagen fibrils could be coated by antibodies to type-I or type-III collagen respectively. The reaction was specific, since antibodies to type-III collagen did not stain type-I collagen fibrils (Plate $1 b$ ), nor did anti-fibrinogen antibodies react with any type of collagen fibrils (Plate 1d). The benzidine stain on the coated type-I collagen fibrils appeared to have some regular spacing, whereas a more compact stain was observed on typeII and -III collagen fibrils. This may reflect density of antigenic determinants on the fibrils. Antisera to type-I collagen possess mainly antibodies to a single determinant at the $C$-terminal end of the molecule (Becker et al., 1972), whereas multiple determinants are recognized in the antibody response to type-II and -III collagens (Hahn et al., 1975; H. Nowack \& R. Timpl, unpublished work).

\section{Inhibition of platelet aggregation by anti-collagen antibodies}

Type-III collagen fibrils were very efficient in aggregating platelets at a concentration as low as $0.5 \mu \mathrm{g} / \mathrm{ml}$. Addition of increasing amounts of antibodies against type-III collagen produced an increasing inhibition of the reaction, and no aggregation was observed after incubation with $2 \mu \mathrm{g}$ of antibody

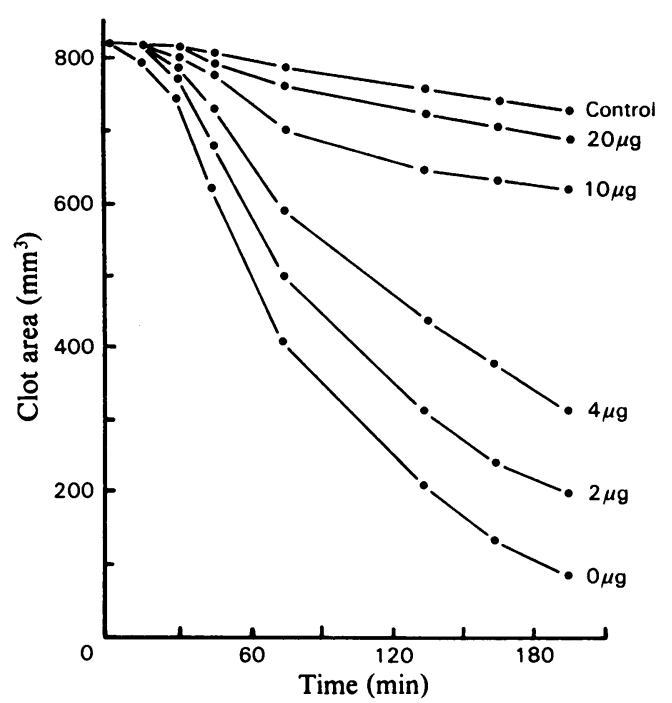

Fig. 3. Inhibition by antibodies against type-II collagen of clot retraction caused by type-II collagen $(20 \mu \mathrm{g})$

The amounts of antibodies added are indicated in the Figure. Control denotes the change in the clot in the absence of collagen and antibodies.

(Fig. 1). Addition of antibodies against type-I collagen, fibrinogen or serum albumin had no effect on the reactions. Inhibition results with comparable specificity were obtained for the aggregation reaction with type-I collagen fibrils (Fig. 1) and with type-II collagen. Only antibodies against the particular collagen used in the tests showed complete inhibition, whereas unrelated antibodies were not inhibitory even when used in 2-3-fold higher amounts. 
We also examined inhibition of aggregating properties of fibrils formed from a solution containing both type-I and type-III collagen. As shown in Fig. 2(a), antibodies to neither type-I collagen nor type-III collagen alone could substantially inhibit the reaction, but a mixture of both antibodies was very efficient. Finally, we have studied monovalent Fab fragments obtained from anti-collagen antibodies and found them to be as active as the intact antibodies (Fig. 2b).

\section{Clot retraction by collagen and its inhibition by anti-} bodies

Fibrin clots formed in the presence of platelets may retract on addition of various aggregating substances (Nyman, 1973). We found that fibrils prepared from various types of collagens also cause clot retraction, as illustrated for type-II collagen in Fig. 3. Here again, clot retraction could be increasingly inhibited by adding increasing amounts of antibodies to type-II collagen. No effect was observed when antibodies to unrelated antigens were added to this reaction.

\section{Discussion}

The data demonstrate that platelet aggregation caused by collagen fibrils could be specifically blocked by coating the fibrils with antibody or Fab fragments. This is in some ways a surprising observation, since soluble immune complexes or aggregated immunoglobulins are usually very potent in aggregating platelets (Lüscher et al., 1973). The interaction is thought to be mediated by $\mathrm{Fc}$ receptors in the platelet membrane (Israels et al., 1973) and can be inhibited to some extent by monomeric immunoglobulin. Presumably the antibodies are arranged on the surface of collagen fibrils in a special array, rendering them incapable of interaction with $\mathrm{Fc}$ receptors but still interfering in the interaction of collagenous structures with platelets by either direct blockade or steric hindrance. It remains to be determined whether further increasing the antibody coat on the fibrils is possible, and whether this could then result in an immune complex capable of aggregating platelets. From the experiments with Fab fragments and with mixtures of antibody-coated and non-coated fibrils (Fig. 2), it can be excluded that antibody-fibril complexes remove, via their Fc sites, secondary factors from the plasma which might be required for efficient collagen-platelet aggregation such as found in some studies with immune complexes (Lüscher et al., 1973). Antibody inhibition of collagen-induced platelet aggregation is also basically different from inhibition of thrombin-induced aggregation by anti-fibrinogen Fab fragments. The fragments do not interfere with proteolytic conversion of surface-bound fibrinogen, but do with polymerization of fibrin (Tollefsen \& Majerus, 1975).
As shown previously, type-I, -II and -III collagen fibrils may vary to some extent in their efficiency to aggregate platelets (Balleisen et al., 1975a; Hugues et al., 1976; Barnes et al., 1976). It was speculated that type-I collagen is actually inactive, and various extents of type-III collagen contamination in the preparations are responsible for the interaction with platelets (Hugues et al., 1976). The specificity of antibody inhibition shown here correlates well with previous immunochemical data (Nowack et al., 1976), and clearly demonstrates that each type of interstitial collagen is able to aggregate platelets. Our data also agree with previous findings where highly purified $\alpha 1$ (I) chains from type-I collagen have been found to aggregate platelets after appropriate renaturation and fibril formation (Balleisen et al., 1976; Fauvel et al., 1978a). Some forms of collagens derived from basement membranes were found not to be active in aggregation (Trelstad \& Carvalho, 1979), whereas other collagens such as type $A_{B_{2}}$ are active ( $L$. Balleisen \& J. Rauterberg, unpublished work).

Antibody coating apparently does not distort the gross structure of the fibrils (Plate 1), indicating that antibodies do not prevent trapping of cells by tightening a loose meshwork of fibrils rather than by competing for collagenous structures at or close to specific platelet-binding sites. The identification of such binding sites was attempted by using collagen $\mathrm{CNBr}$ peptides in assays other than direct platelet aggregation, since such peptides cannot be examined in fibrillar form. Activity was mainly found in peptide $\alpha 1$ (III)-CB4 of type-III collagen (Fauvel et al., $1978 b$; L. Balleisen, unpublished work), whereas results for type-I collagen are still controversial and show activity in the $C$-terminal peptide $\alpha 1(\mathrm{I})$-CB6 (Balleisen et al., 1975b; Fauvel et al., 1978a) as well as in the glycopeptide $\alpha 1$ (I)-CB5 (Chiang \& Kang, 1976). These data do not necessarily indicate that the same sites are involved in the aggregation reaction. The preparation of antibodies to single antigenic determinants of collagen is feasible (Timpl, 1976) and should allow localization by inhibition assays of such sites in fibrils, particularly when Fab fragments are used instead of the bulkier antibodies.

Native fibrils formed in vitro from either type-I or type-III collagen do not differ in cross-striation banding (Wiedemann et al., 1975). It is therefore still impossible to decide by electron microscopy whether both collagens are assembled in vitro or in vivo in independent fibrillar structures. Immunofluorescence has indicated that type I and -III collagens in tissues are localized in different anatomical regions (Timpl et al., 1977), but these studies have not yet been extended to the ultrastructural level. Antibody inhibition of platelet aggregation by fibrils prepared from a mixture of type-I and -III collagens (see Fig. 2) suggests that formation of mixed-type fibrils has not occurred to a substantial degree. Thus specific anti- 
body reagents may be versatile tools with which to study various biological properties of interstitial collagens.

This study was supported by grants of the Deutsche Forschungsgemeinschaft (projects Ti 95/3 and $\mathrm{Ba}$ 631/1).

\section{References}

Balleisen, L., Gay, S., Marx, R. \& Kühn, K. (1975a) Klin. Wochenschr. 53, 903-905

Balleisen, L., Marx, R. \& Kühn, K. (1975b) Blut 31, 95-106

Balleisen, L., Marx, R. \& Kühn, K. (1976) Haemostasis 5, 155-164

Barnes, M. J., Gordon, J. L. \& MacIntyre, D. E. (1976) Biochem. J. 160, 647-651

Becker, U., Timpl, R. \& Kühn, K. (1972) Eur. J. Biochem. 28, 221-231

Beil, W., Timpl, R. \& Furthmayr, H. (1973) Immunology 24, 13-24

Born, G. V. R. \& Gross, M. J. (1963) J. Physiol. (London) 168, 178-195

Brass, L. F. \& Bensusan, H. B. (1974) J. Clin. Invest. 54, 1480-1487

Chiang, T. M. \& Kang, A. H. (1976) J. Biol. Chem. 251, 6347-6351

Edelman, G. M. \& Marchalonis, J. J. (1967) Methods Immunol. Immunochem. 1, 419-420

Fauvel, F., Legrand, Y. J. \& Caen, J. P. (1978a) Thromb. Res. 12, 273-285

Fauvel, F., Legrand, Y. J., Bentz, H., Fietzek, P. P., Kühn, K. \& Caen, J. P. (1978b) Thromb. Res. 12, 841-850

Fietzek, P. P. \& Kühn, K. (1976) Int. Rev. Connect. Tissue Res. 7, 1-60

Gay, S., Balleisen, L., Remberger, K., Fietzek, P. P., Adelmann, B. C. \& Kühn, K. (1975) Klin. Wochenschr. 53, 899-902
Gordon, J. L. \& Dingle, J. T. (1974) J. Cell Sci. 16, 157-166

Graham, R. C. \& Karnovsky, M. J. (1966) J. Histochem. Cytochem. 14, 291-302

Hahn, E., Nowack, H. \& Timpl, R. (1975) Immunology 28, 561-568

Hessel, B. \& Blombäck, B. (1971) FEBS Lett. 18, 318-320

Hugues, J., Herion, F., Nusgens, B. \& Lapiere, C. M. (1976) Thromb. Res. 9, 223-231

Israels, E. D., Nisli, G., Parakevas, F. \& Israels, L. G. (1973) Thromb. Diath. Haemorrh. 29, 434-444

Jaffe, R. M. \& Deykin, D. (1974) J. Clin. Invest. 53, 875883

Lüscher, E. F., Pfueller, S. L. \& Massini, P. (1973) Ser. Haematol. 4, 382-319

Michaeli, D. \& Orloff, K. G. (1976) Prog. Hemostasis Thromb. 3, 29-59

Miller, E. J. (1972) Biochemistry 11, 4903-4909

Miller, E. J. (1976) Mol. Cell. Biochem. 13, 165-192

Muggli, R. \& Baumgartner, H. R. (1973) Thromb. Res. 3, 715-728

Nowack, H., Gay, S., Wick, G., Becker, U. \& Timpl, R. (1976) J. Immunol. Methods 12, 117-124

Nyman, D. (1973) Thromb. Res. 2, 323-329

Sharp, A. A., Warren, B. A., Paxton, A. M. \& Allington, M. J. (1968) Lancet i, 493-499

Timpl, R. (1976) in Biochemistry of Collagen (Ramachandran, G. N. \& Reddi, A. H., eds.), pp. 319-375, Plenum Press, New York

Timpl, R., Glanville, R. W., Nowack, H., Wiedemann, H., Fietzek, P. P. \& Kühn, K. (1975) Hoppe-Seyler's Z. Physiol. Chem. 356, 1783-1792

Timpl, R., Wick, G. \& Gay, S. (1977) J. Immunol. Methods 18, 165-182

Tollefsen, D. M. \& Majerus, V. W. (1975) J. Clin. Invest. 55, $1259-1268$

Trelstad, R. L. \& Carvalho, A. C. A. (1979) J. Lab. Clin. Med. 93, 499-505

Wiedemann, H., Chung, E., Fujii, T., Miller, E. J. \& Kühn, K. (1975) Eur. J. Biochem. 51, 363-368 